This behaviour is precisely that which was found experimentally for the order parameter $M$ in a recent systematic study of the phase transition in thin $\mathrm{Fe}$ films on $A u(100)$. Fig. 5 shows the temperature dependence of the magnetization in the vicinity of the transition temperature, $T_{c}$, for films of various thicknesses. A log-log scale is used where power laws would be represented by straight lines whose slope is the critical exponent $\beta$. From the Figure, the power law nature of the vanishing of $M$ and the independence of $\beta$ on the film thickness are evident. Thin Fe films on $\mathrm{Au}(100)$ therefore represent a physical realization of a 2-d form of universality.

\section{Conclusions}

Research on the magnetic properties of layered structures has produced a wealth of exciting new results and this paper by no means offers an exhaustive compilation. For instance, we have largely neglected multilayers of the types illustrated in Fig. 1.

The complexity of multilayers has been highlighted in recent experiments by $\mathrm{P}$. Grünberg, C. Carbone and coworkers at Jülich on $\mathrm{Fe}-\mathrm{Cr}$ systems which revealed a magnetic coupling between the $\mathrm{Fe}$ layers through the $\mathrm{Cr}$. As a result of this coupling an entire new class of phenomena arises, not anticipated by the present discussion of single layers.

The essential message however, summarized by Fig. 5 , is that truly $2-d$ magnetic systems are now within the reach of modern experimental physics.

\section{FURTHER READING}

Experimental magnetic properties: Magnetism in Ultrathin Films, Special Issue of Appl. Phys. A 49, Ed. P. Pescia (Nov./Dec. 1989).

Gradmann U. et al., Thin Solid Films 126 (1985) 107.

Pescia D. et al., IFF Bulletin (KFA Jülich) 33 (1988).

\section{Thin film growth:}

Germar R. et al., Appl. Phys. A 47 (1988) 393.

Purcell S.T. et al., J. Vac. Sci. Technol. B6 (1988) 794.

Ground state magnetic properties:

Freeman A.J. et al., in Polarized Electrons in Surface Physics, Ed. R. Feder (World Scientific, Singapore) 1985.

2-d magnetism at finite temperatures: Pokrovskii V.L. et al., in Spin Waves and Magnetic Excitations, Modern Problems in Condensed Matter Sciences, Vol. 22.2, Eds. A.S. Borovik-Romanov, S.K. Sinha (North-Holland, Amsterdam) 1988.

\title{
Course Restructuring
}

An interim report of tertiary level physics education in the UK recommends:

— remedial teaching of mathematics in universities and polytechnics;

- a $30 \%$ reduction in content of the three year undergraduate course;

- an additional year which could either be a fourth year to a three year core course, or a more intensive one year course that may or may not form part of a Masters of Physics preceding the doctorate programme.

The report was prompted by the changeover to a shallow, broader school syllabus, and a concern that UK physics degrees compare poorly with continental counterparts at a time when mobility at a European level is being encouraged. It was prepared by a joint working party, chaired by Professor Chambers of the Physics Department, University of Bristol, made up of representatives from the Institute of Physics, the Standing
Committee of University Professors and the Committee of the Heads of Polytechnics. The report was released in April to British universities to allow them to submit appropriate proposals for the next round of government funding.

Financial aspects will dominate further discussions on how to implement the recommendations. Meanwhile, the working party will consider the 'reduced content' syllabus in time to make a final report in September 1990.

Another report dealing partly with physics education is due to be released next month. This time it is the Action Committee on Science and Technology that is examining scientific manpower needs in the UK. Meanwhile, the EPS's very own Action Committee for Physics Education is preparing a major survey at the European level. It will mirror in many vital respects the British considerations.

\section{Paul Scherrer's 100th Anniversary}

More than 400 former students of Professor Paul Scherrer met on 3 February 1990 at the ETH, Zürich to celebrate the 100th anniversary of his birth. Among them were about 90 physicists who wrote their Ph.D. theses under his supervision while he was professor of experimental physics at the ETH from 1920 to 1960 . They came from all over the world to pay tribute to an excellent teacher and to a man with many outstanding human qualities, enthusiasm, drive and humour. It was very gratifying that his daughter Mrs. Ines Jucker-Scherrer was also with us.

But who was Paul Scherrer and why does he mean so much to Swiss physicists? In a small country like Switzerland, physics could only develop to a high international standard if in the critical era of the twenties when physics was undergoing revolutionary changes, a competent, enthusiastic and dynamic person held the key position of professor of experimental physics at the ETH. Switzerland was indeed fortunate that in 1920 Paul Scherrer, together with Professor Debye, was called to Zürich to succeed Professor Weiss. He built up a successful institute and in the 40 years of his activity many young Ph.D. students obtained a solid training in physics to allow them to find important positions all over the world. Scherrer's initiative in 1927 led to the appointment of Wolfgang Pauli as professor of theoretical physics at the ETH, thus making Zürich one of the leading centres in Europe.

Scherrer was not only a leader of physics in Switzerland but also an "internationalist" who took on the rôle of an international mediator. For example, he organized the first international conferences that took place in Zürich after each World War. Scherrer was also one of the founders of
CERN and was instrumental in the choice of Geneva for its site.

Everybody was in a happy and somewhat nostalgic mood and wanted to hear lively, exiting and enthusiastic lectures in the style of Scherrer. This was accomplished by the programme of lectures put together by an organizing committee of former assistants under Kurt Alder.

The main speakers were O. Huber, W.J. Merz, F. Boehm, J.-P. Blaser and H. Albers.

A highlight of the occasion was the talk by Victor Weisskopf who became a personal friend of Scherrer when he was Pauli's assistant in the 1930's. The title _ "The great art to make physics understandable" - was appropriate since Scherrer's main aim was to teach students good physics using clear and lively lectures and demonstrations. It was for this reason that Scherrer's lectures were attended by many students, not only of physics but also from other faculties. Movies taken in the 1940's of a number of entertaining skiing, swimming and hiking excursions made by Scherrer's institute completed a memorable and highly enjoyable evening.

W.J. Merz, Zürich

\section{Akzo Research Joins}

Akzo Research Laboratories Arnhem, the main central research laboratories of Akzo Nederland bv, is to become an Associate Member of EPS. The managerial contact is Ir. E. van Andel, Director of Corporate Research, and the scientific contact is Ir. R.O. van Hasselt, Head of the Department of Applied Physics that is very active in aspects of polymer physics related to fibre technologies. 